\title{
ECONOMÍA DEL CONOCIMIENTO Y NUEVOS CONTRASTES TERRITORIALES EN ESPAÑA: UNA PERSPECTIVA MULTIESCALAR ${ }^{1}$
}

\author{
Ricardo Méndez Gutiérrez del Valle \\ Instituto de Economía, Geografía y Demografía \\ Centro de Ciencias Humanas y Sociales CSIC \\ ricardo.mendez@cchs.csic.es
}

\section{RESUMEN}

En los últimos años la economía del conocimiento ha sido objeto de creciente atención desde el punto de vista del desarrollo regional y urbano. El artículo propone un análisis del empleo en aquellas actividades intensivas en conocimiento para identificar su importancia actual en los diferentes territorios, así como la lógica espacial que determina su distribución. El estudio se realiza a dos escalas espaciales: por un lado, se consideran las provincias españolas y, por otro, el sistema urbano en su conjunto, tomando como referencia las áreas urbanas definidas por el Ministerio de Fomento. La combinación de ambas perspectivas permite matizar la habitual referencia a la concentración espacial de estas actividades, revisar de forma crítica algunas interpretaciones teóricas y proponer futuras líneas de investigación.

Palabras clave: economía del conocimiento, desarrollo territorial, áreas urbanas, España.

\section{ABSTRACT}

Over the last years the knowledge economy have been receiving increasing attention from the point of view of regional \& urban development. The article proposes an analysis of knowledge intensive clusters in order to clarify the current importance and, especially, the spatial logic that determines its territorial distribution. The study was performed at two spatial scales: on the one hand, it focuses on spanish provinces and, the other hand, the urban

Fecha de recepción: octubre 2011.

Fecha de aceptación: julio 2012.

1 El artículo forma parte del proyecto de investigación financiado por el Plan Nacional de I+D+i sobre Las regiones metropolitanas españolas en la sociedad del conocimiento: tendencias económicas y transformaciones territoriales (CSO2009-10888). 
system, with reference to the urban areas defined by the Ministerio de Fomento. The complementary use of both perspectives, allows us to offer a more nuanced vision of the habitual reference to the spatial concentration of these activities, propose a critical approach to theoretical bibliography and new perspectives for future research.

Key words: knowledge economy, territorial development, urban areas, Spain.

\section{INTRODUCCIÓN}

Desde el inicio de la pasada década, en la Unión Europea se plantea la necesidad de avanzar hacia una economía más basada en la generación, difusión y aplicación de diferentes formas de conocimiento como respuesta a los retos y amenazas de una globalización que cuestiona algunas de sus tradicionales ventajas competitivas, así como al cambio en la demanda interna de bienes y servicios. Al tiempo, generar empleo suficiente y de mayor calidad, que compense las pérdidas derivadas de la deslocalización de ciertas actividades y la creciente precarización laboral, también se asocia a un recurso como el conocimiento, ahora valorado como estratégico. En España, que padece el agotamiento de un modelo basado en la producción inmobiliaria masiva, el endeudamiento de familias y empresas y el crecimiento de los servicios al consumo, con baja productividad, empleo de escasa calidad y graves impactos ambientales, esa necesidad de evolucionar hacia una nueva economía resulta aún más evidente, aunque también lo sean las dificultades para lograrlo.

Para identificar la importancia que alcanza esa economía del conocimiento en los diferentes territorios, tres suelen ser las principales dimensiones consideradas. Un primer indicador es la presencia de aquellas industrias y servicios intensivos en el uso del conocimiento dentro de su estructura económica. Un segundo indicador es la proporción de trabajadores cualificados entre la población ocupada, cualquiera que sea su sector de actividad, al considerar que el capital humano es el factor clave para su impulso. Finalmente, también puede valorarse mediante la inversión dedicada a la I+D+i y sus resultados en forma de innovaciones que mejoren la productividad, la capacidad exportadora, la generación de patentes, etc.

Pueden plantearse, por tanto, diversas aproximaciones a la desigual importancia, características y dinamismo de la economía del conocimiento en regiones y ciudades, lo que justifica abordar un análisis monográfico de las actividades intensivas en conocimiento y su comportamiento territorial, tal como se hace en este texto. Ya desde el trabajo pionero de Machlup (1962), su identificación ha estado sometida a debate. La ambigüedad procede del hecho de que para algunos autores se considera actividades intensivas en conocimiento a aquellas que lo producen en mayor medida, mientras en otros casos se consideran también aquellas otras que lo incorporan y transfieren a sus procesos de trabajo, lo que amplía el criterio de selección (Winden et al., 2006). Entre las diversas opciones existentes, aquí se han tomado como base las clasificaciones elaboradas por organismos internacionales como la OCDE (1996) o la UNCTAD (2008), que suponen aproximaciones complementarias.

En consecuencia, dentro de este conjunto se incluyen las industrias de mayor intensidad tecnológica (tecnologías de información y comunicación; farmacéutica y biotecnología; aeronáutica y aeroespacial; instrumentos de precisión; fabricación de maquinaria y equipos; automoción; química), los servicios intensivos en conocimiento (servicios avanzados a 
empresas; finanzas y seguros; educación) y un sector cultural hoy integrado en la economía creativa (actividades de creación y artísticas; bibliotecas, archivos y museos; industria editorial, audiovisual y multimedia; medios de comunicación). Al tratarse de información analizada a escala local, la desagregación que ofrece la Tesorería General de la Seguridad Social sólo alcanza los dos dígitos de la CNAE-2009, por lo que actividades como las educativas se incluyeron en su totalidad debido a la elevada presencia de titulados superiores en todos los niveles educativos, mientras que no se consideraron otras como las sanitarias (por contar con una presencia minoritaria de titulados superiores entre sus trabajadores), o ciertas industrias que cuentan con un segmento altamente especializado e innovador, ligado a la moda (confección, calzado...), que no es posible diferenciar de la producción en serie, ampliamente predominante.

Con este contexto, el objetivo del artículo es analizar la organización territorial de estas actividades en España a diferentes escalas, respondiendo a tres tipos de preguntas: qué importancia alcanzan hoy desde la perspectiva del empleo y cuál ha sido su evolución reciente; dónde se localizan, por qué y qué otros territorios quedan al margen de las estrategias de empresas e instituciones vinculadas a estos sectores; qué implicaciones tiene para la competitividad, el nivel de vida o la calidad del empleo de regiones y ciudades.

Para lograrlo, el primer apartado propone una breve reflexión teórica sobre las lógicas espaciales que justifican su distribución, revisa de forma crítica algunas afirmaciones excesivas sobre sus positivos impactos en los territorios donde se asienta y define las hipótesis a contrastar. El segundo apartado resume tendencias recientes de la economía española y destaca el volumen que representan hoy las actividades intensivas en conocimiento, mientras el tercero analiza los fuertes contrastes interprovinciales e interurbanos en su localización, que evidencian la importancia de las externalidades asociadas a la aglomeración pero también el significado de otros factores de atracción localizados en determinadas ciudades de tamaño intermedio, poco atendidos en la bibliografía disponible. Se plantea, por último, un análisis estadístico multivariante para buscar posibles asociaciones espaciales entre la presencia de estas diversas actividades, la densidad de población, empleo o producción del territorio, así como diversos indicadores socioeconómicos y laborales ${ }^{2}$. Las conclusiones valoran la importancia que mantienen las estrategias espaciales para actividades en gran medida desmaterializadas, destacan la importancia de las industrias intensivas en tecnología y cuestionan algunas supuestas evidencias sobre la relación entre economía del conocimiento y desarrollo territorial.

\section{EL MAPA DE LAS ACTIVIDADES INTENSIVAS EN CONOCIMIENTO: CLAVES EXPLICATIVAS Y ALGUNOS DEBATES}

Las actividades intensivas en conocimiento se caracterizan por una organización espacial que responde a estrategias diferenciadas y genera transformaciones territoriales significativas, así como nuevos contrastes allí donde alcanzan cierta importancia, si bien las investigaciones sobre su distribución en las regiones o los sistemas urbanos son escasas y

2 En el tratamiento inicial de la base de datos colaboró Jesús Tébar y para realizar el análisis multivariante se contó con el asesoramiento de la Unidad de Estadística del Centro de Ciencias Humanas y Sociales del CSIC. 
las interpretaciones propuestas suscitan ciertas controversias. Para España se cuenta con una aproximación general a la economía del conocimiento para el conjunto de ciudades que superan los 20.000 habitantes, que analiza la localización de estas actividades junto con la del capital humano, la inversión y resultados de la innovación o la dotación de infraestructuras digitales, estableciendo como resultado una tipología según comportamientos (Méndez y Sánchez Moral, 2011). En una perspectiva diferente pueden mencionarse otros estudios sobre el reparto de las actividades integradas en la economía creativa (Boix et al., 2010), así como de la supuesta clase creativa identificada por Florida y su asociación espacial con indicadores de tecnología, talento y tolerancia (Pesquera et al., 2010).

En la bibliografía internacional, tres son los argumentos más reiterados sobre las pautas que predominan en su distribución espacial y los impactos generados sobre el territorio, que son otras tantas hipótesis a discutir a partir del análisis aquí realizado: una fuerte tendencia a la concentración, la existencia de trayectorias locales específicas, ligadas a las herencias de cada territorio, lo que se traduce en especializaciones persistentes en el tiempo, o sus positivos efectos sobre la atracción del talento, la mejora de los ingresos y la mayor calidad del empleo generado.

a) Los procesos de concentración espacial y sus límites.

El rasgo que mejor identifica el comportamiento espacial de las actividades intensivas en conocimiento es, sin duda, su tendencia a la aglomeración en unas pocas regiones, que suelen coincidir con las más prósperas y con mayor dotación de todo tipo de recursos, tanto materiales como inmateriales. A escala del sistema urbano, se constata una similar primacía de las principales aglomeraciones metropolitanas frente a su rápida disminución al descender en la jerarquía; en su interior, las grandes ciudades tienden a ejercer un similar efecto de atracción, limitando así el desarrollo de estructuras más policéntricas; finalmente, dentro de éstas resulta frecuente su agrupamiento en determinados barrios, siendo utilizadas incluso por algunas políticas de regeneración urbana para dinamizar áreas deterioradas, con efectos de revalorización económica y sustitución social a menudo contradictorios (Swyngedouw et al., 2002).

La consecuencia es que este tipo de actividades, así como los trabajadores altamente cualificados que trabajan en ellas, alcanzan una importancia creciente para definir la nueva jerarquía urbana. Según Scott, «proporciones significativas del empleo total en las mayores áreas metropolitanas se concentran en servicios de alto nivel y actividades culturales; en las pequeñas áreas urbanas, por el contrario, la mayor parte de los perfiles profesionales siguen estando dominados por las actividades industriales y similares», si bien «esas pequeñas áreas urbanas también muestran una enorme variedad de formas individuales de especialización económica» (Scott, 2009: 207).

Las explicaciones sobre esa acusada polarización del empleo señalan, sobre todo, la importancia de los calificados como hard location factors, relacionados con los recursos materiales del territorio (Musterd y Murie, 2010). Señalan así las externalidades positivas asociadas a la presencia de infraestructuras y servicios de calidad, una oferta inmobiliaria amplia, o instituciones universitarias y de $\mathrm{I}+\mathrm{D}+\mathrm{i}$ presentes en el territorio. Pero la atención se ha desplazado hacia los soft location factors, de carácter más intangible, que destacan influencia que sobre la presencia de capital humano altamente cualificado tienen la calidad 
de vida y las amenidades urbanas, la diversidad sociocultural, la tolerancia, etc., con la consiguiente localización de las empresas que los emplean (Florida, 2005).

Resulta, en cambio, poco abordada la relevancia que también alcanzan ciertas ciudades de tamaño intermedio, generalmente monoespecializadas en una determinada rama de actividad. Frente a las limitaciones de escala o su imagen tradicional como espacios poco creativos e innovadores, determinados estudios han comenzado a demostrar la capacidad de algunas de ellas para generar condiciones locales que permiten el desarrollo de estos sectores. Por un lado, la mejora de las redes de transporte y, sobre todo, de información y comunicación han eliminado algunas restricciones asociadas a su baja accesibilidad, permitiendo instalar en ellas empresas plenamente competitivas, a lo que también contribuyen los procesos de segmentación y deslocalización desde las grandes urbes. La inversión pública realizada en servicios y equipamientos de calidad, junto al creciente nivel educativo y de ingresos de su población, o la mejora de su imagen desde el punto de vista ambiental y de calidad de vida, reduce también algunas de sus tradicionales desventajas competitivas con el mundo metropolitano. Por último, la capacidad dinamizadora de algunos gobiernos de proximidad para generar redes de colaboración locales, poner en valor sus recursos patrimoniales e impulsar las actividades culturales y creativas también debe ser explorada (Méndez dir., 2010).

b) Redes localizadas, clusters de conocimiento y diversidad de trayectorias territoriales.

Junto al proceso de concentración, parece también confirmada la tendencia a que ciertos tipos de actividades se agrupen en determinados territorios, base para la formación de clusters de conocimiento localizados que, más allá de su dimensión, presentan características específicas. La clave de estos procesos parece estar en las economías de localización que se derivan de la complementariedad entre empresas que trabajan en torno al mismo tipo de productos o servicios, así como en las economías de urbanización asociadas a la densidad y diversificación de sus mercados de trabajo y consumo locales, o la presencia de servicios de valor añadido y centros de $\mathrm{I}+\mathrm{D}+\mathrm{i}$ vinculados a esa demanda específica, lo que puede aumentar las interacciones y generar rendimientos crecientes (Boschma y Kloosterman eds., 2005).

Es indudable que todo cluster local está integrado en redes multiescalares que desbordan cualquier área urbana y la relacionan de forma cada vez más intensa a proveedores, mercados y fuentes de capital o conocimiento externos, lo que resulta de especial importancia en el tipo de actividades aquí consideradas, por lo que su plena comprensión exige un análisis multiescalar (Vale, 2011). Pero aceptar que los territorios densifican progresivamente sus interrelaciones y desdibujan la influencia de la proximidad física no significa olvidar la importancia del lugar, de sus recursos y actores, o de las características socioculturales e institucionales heredadas, que generan trayectorias específicas en la evolución de las economías regionales y urbanas, tal como plantean los enfoques evolucionistas y el concepto de path dependence (Simmie et al., 2008). En la perspectiva aquí planteada, esto puede explicar el diverso perfil de los territorios en cuanto a presencia de las diferentes actividades intensivas en conocimiento según su particular historia y el patrimonio material e inmaterial disponible, generadores de especializaciones persistentes ligadas a un saber hacer, una cultura y unas instituciones específicas. 
En tal sentido, al considerar esta influencia de las condiciones propias de cada territorio cobra especial importancia la desigual capacidad mostrada por las coaliciones de actores con mayor capacidad de influencia para -en el marco de las relaciones de poder que se establecen- impulsar formas de gobernanza que favorezcan la puesta en valor de los recursos locales en conocimiento, cultura o creatividad, así como políticas de promoción y ordenación explícitas para el desarrollo de este tipo de actividades frente a otras alternativas posibles.

c) Economía del conocimiento y desarrollo regional/urbano: algunas tesis en revisión.

Además de presentar unas pautas de localización relacionadas con factores como los señalados, las actividades intensivas en conocimiento parecen asociarse a otras características socioeconómicas de los territorios, tal como destaca buena parte de la bibliografía disponible. Desde el trabajo de Florida (2002) sobre la geografía del talento, han sido numerosos los intentos de demostrar que, tanto las actividades generadoras de un elevado valor añadido como los profesionales altamente cualificados, se concentran en las mismas áreas urbanas, donde originan un crecimiento más estable y una productividad superior al promedio, junto a un aumento del nivel medio de ingresos y mayor calidad del empleo, . Eso se traducirá en mayor proporción de contratos indefinidos y menor riesgo de desempleo en las fases recesivas del ciclo económico. Aunque la mayoría de tales estudios basan sus resultados en el establecimiento de correlaciones estadísticas, las interpretaciones que se aportan ofrecen a menudo supuestas relaciones de causalidad en las que unos trabajadores del conocimiento (Stehr, 2002) flexibles, móviles y atraídos no sólo por la oferta de buenos empleos, sino también por la calidad de vida local, son la clave de la que se derivan ese tipo de efectos.

Sin cuestionar las ventajas comparativas genéricas que una especialización en economía del conocimiento puede suponer respecto a otras intensivas en el uso de trabajo barato/ precario, o con fuerte impacto ambiental, resulta más discutible el sesgo determinista de afirmaciones como las anteriores, favorecedoras de cierta mitificación respecto a los efectos esperables de este tipo de actividades (Laroche, 2001). Se ofrece así una imagen demasiado lineal de la relación entre conocimiento y desarrollo territorial, sometida a una revisión crítica desde, al menos, tres perspectivas complementarias.

Por un lado, la diversidad de comportamientos que caracteriza a las diferentes actividades que integran esa caja negra denominada economía del conocimiento puede suponer también impactos socioeconómicos muy desiguales según los casos, que sólo saldrán a la luz al realizar un análisis desagregado de las mismas. Al tiempo, algunos estudios de los últimos años sobre «el empleo realmente existente» (Castillo, 2005) en estos sectores han puesto en evidencia condiciones de trabajo y tipos de contratación en los que no están ausentes diversas formas de precariedad, explicables sobre todo a partir de la evolución seguida por el sistema de relaciones laborales. Finalmente, una parte significativa de los puestos de trabajo en las actividades intensivas en conocimiento siguen siendo de baja cualificación, lo que puede derivar en cierta dualización interna de las condiciones laborales e introducir así una mayor complejidad que no acepta interpretaciones demasiado simplistas. La investigación que se presenta aborda este conjunto de cuestiones en una panorámica general que aspira, sobre todo, a servir como base a investigaciones más pormenorizadas que profundicen en las diversas lógicas territoriales y en su interpretación. 


\section{TENDENCIAS RECIENTES DEL EMPLEO EN ESPAÑA: ¿DE LA TERCIARIZACIÓN A UNA ECONOMÍA DEL CONOCIMIENTO?}

La primera década del siglo ha sido un periodo de fuertes contrastes desde la perspectiva del empleo en España. Como reflejo del rápido crecimiento económico iniciado a mediados del decenio anterior, intensivo en mano de obra y sin apenas incremento de la productividad, la afiliación a la Seguridad Social creció desde los 15,1 millones en 2000 hasta los 19,2 millones en 2007, lo que supuso una tasa del 27,2\% (hasta el 55,6\% desde 1995). El inicio de la crisis financiera internacional, agravada aquí por la dimensión de la burbuja inmobiliaria (López Hernández y Rodríguez, 2010), puso un brusco final a esa tendencia expansiva con la pérdida de más de un millón de afiliaciones en apenas dos años, hasta quedar en 17,9 millones al terminar 2009 (-6,5\%). Por su parte, el paro registrado se mantuvo en torno a los dos millones de personas en los años de bonanza económica para crecer hasta los 3,6 millones en 2009, un 85,6\% por encima del promedio alcanzado en el año $2000^{3}$ Desde una perspectiva sectorial, dos fueron las tendencias a destacar en estos años. En primer lugar, se reforzó el proceso de terciarización del empleo iniciado décadas atrás, que aún se intensificó desde el inicio de la crisis ante su mayor impacto sobre los sectores productivos. Si en el cambio de siglo los 9,5 millones de afiliados que trabajaban en el sector de servicios ya representaban un $63,1 \%$ del total, esa proporción alcanzó el 66,8\% en 2007 y el 70,0\% al finalizar 2009, con 12,5 millones de trabajadores ${ }^{4}$. Dentro de las actividades productivas, al secular retroceso del sector agrario se añadió la estabilización del empleo industrial en unos 2,7 millones de afiliados durante los años de crecimiento, con cierta disminución en términos relativos (del 17,6\% al $14,1 \%$ de la afiliación total), por contraste con el notable crecimiento del empleo en construcción y obras públicas, tanto en términos absolutos (de 1,6 a 2,5 millones de afiliados) como relativos (del 10,7\% al 12,8\%). Su posterior hundimiento (-674.500 afiliados entre 2007 y 2009) volvió a restaurar en parte la situación precedente, pero la debilidad del tejido industrial y el freno de la demanda interna, causantes de una reducción de su empleo (-307.600), mantuvieron una cifra de 74,2 afiliados en construcción por cada cien industriales al finalizar 2009.

No obstante, calificar a la española como una economía de servicios apenas ayuda a comprender el sentido de las tendencias recientes si no se lleva a cabo la desagregación de un conjunto tan heterogéneo como éste y el establecimiento de tipologías que le doten de sentido, tal como han intentado numerosas propuestas en esa dirección (Glückler y Hammer, 2011). Al tiempo, las simples cifras de empleo minusvaloran el significado que aún mantiene parte de la industria como fuente de innovaciones, elevada productividad, capacidad exportadora, empleo estable y mercado para servicios empresariales de valor añadido localizados

3 Aunque 2009 es el año de referencia para el que pudo disponerse de toda la información utilizada, en relación a estos dos indicadores resulta significativo destacar que al finalizar 2011 el promedio de afiliados a la Seguridad Social se había reducido a 17,1 millones y el paro registrado se había elevado hasta 4,4 millones de personas en España, por el continuado efecto de la crisis económica.

4 En un pormenorizado estudio sobre los servicios en las regiones españolas, Cuadrado Roura y Maroto (2010) reducen esa cifra a algo más del 65\% de los ocupados en 2008 al utilizar una fuente distinta (BD.MORES, base 2000), elaborada por el Ministerio de Economía y Hacienda. 
en su entorno. Por ese motivo, propuestas de carácter transversal como la que plantea el concepto de economía del conocimiento, que integra tanto actividades industriales como de servicios intensivas en el uso de este recurso, pueden evitar el sesgo que supone mantener una visión dual inadecuada para interpretar las nuevas lógicas territoriales y los principales contrastes resultantes (Krätke, 2007).

Así, las actividades intensivas en conocimiento sumaron 211.983 empresas y 3.129.065 afiliados al finalizar 2009, el 12,1\% y $18,0 \%$ del total respectivamente (tabla 1). El hecho de que sólo representen una de cada ocho empresas y apenas uno de cada cinco puestos de trabajo supone una importancia aún modesta, reflejo del modelo de crecimiento dominante en las últimas décadas. No obstante, en una perspectiva dinámica el diagnóstico es más optimista pues en el transcurso de la última década las ocupaciones en actividades intensivas en conocimiento crecieron en torno al medio millón de afiliaciones, aumentando también su peso relativo (desde el 17,3\% en 2000).

Tabla 1

EMPLEOS EN ECONOMÍA DEL CONOCIMIENTO EN ESPAÑA, 2009.

\begin{tabular}{|l|r|r|r|r|}
\hline Actividades intensivas en conocimiento & \multicolumn{1}{|c|}{$\begin{array}{c}\text { Número de } \\
\text { empresas }\end{array}$} & \multicolumn{1}{c|}{$\begin{array}{c}\text { \% } \\
\text { total }\end{array}$} & \multicolumn{1}{c|}{$\begin{array}{c}\text { Número de } \\
\text { afiliados }\end{array}$} & \multicolumn{1}{c|}{$\begin{array}{c}\text { \% } \\
\text { total }\end{array}$} \\
\hline Industrias alta y media-alta IT & 20.494 & 1,17 & 558.050 & 3,20 \\
Servicios avanzados a empresas & 112.200 & 6,43 & 1.098 .337 & 6,31 \\
Finanzas y seguros & 18.728 & 1,07 & 435.788 & 2,50 \\
Educación & 36.457 & 2,09 & 742.867 & 4,27 \\
Actividades culturales & 24.104 & 1,38 & 294.023 & 1,69 \\
\hline Total Economía del Conocimiento & $\mathbf{2 1 1 . 9 8 3}$ & $\mathbf{1 2 , 1 5}$ & $\mathbf{3 . 1 2 9 . 0 6 5}$ & $\mathbf{1 7 , 9 7}$ \\
\hline Restantes actividades & 1.532 .813 & 87,85 & $14,284.848$ & 82,03 \\
\hline Total & 1.744 .796 & 100 & 17.413 .913 & 100 \\
\hline
\end{tabular}

Fuente: Tesorería General de la Seguridad Social.

Dentro de ese conjunto, los servicios avanzados a empresas representan la actividad principal, con más de un tercio de los afiliados $(35,1 \%)$ y un $25,9 \%$ de aumento desde el año 2000 , reflejo de las crecientes exigencias competitivas y los procesos de externalización en numerosas empresas. También las entidades financieras y de seguros conocieron cierto aumento del empleo $(11,5 \%)$ en esos años, aunque bastante inferior al registrado por un sector educativo que con un $62,4 \%$ fue el más dinámico, seguido de cerca por las actividades ligadas a la cultura, que crecieron otro $60,9 \%$, con fuerte presencia del sector público en ambos casos. Como contrapunto, la única actividad en retroceso fue la industrial, pues las ramas de alta y media-alta intensidad tecnológica redujeron un $21,0 \%$ sus trabajadores, reflejo de la intensidad de unos procesos de deslocalización que no afectaron sólo a actividades más tradicionales y de menor valor añadido. En definitiva, la economía del conocimiento consolida su presencia en España, si bien de forma moderada y cierta heterogeneidad entre las actividades que la integran, que vuelve a repetirse al considerar su comportamiento espacial. 


\section{DISTRIBUCIÓN ESPACIAL DEL EMPLEO EN ACTIVIDADES INTENSIVAS EN CONOCI- MIENTO: CONCENTRACIÓN VS. ESPECIALIZACIÓN}

Pese a tratarse de entidades administrativas de rango intermedio delimitadas hace casi dos siglos, las provincias españolas aún constituyen unidades espaciales útiles para analizar las pautas de localización características de las actividades que comprende la economía del conocimiento antes de precisar la diversidad de trayectorias urbanas subyacentes. A esta escala, el primer rasgo que caracteriza la localización de estas actividades es su acusada tendencia a la concentración, reflejo de los diversos tipos de externalidades positivas que conlleva la aglomeración pese a tratarse en la mayoría de ocasiones de empresas o instituciones que operan con bienes inmateriales y se basan en recursos intangibles.

De los 3,1 millones de afiliados que suman, 766.673 trabajan en la provincia de Madrid y otros 550.425 en la de Barcelona, lo que supone el 42,1\% del total (tabla 2). Si a éstas se añaden las otras nueve provincias que también superan el $2 \%$ de la cifra correspondiente a España (Valencia, Sevilla, Vizcaya, Zaragoza, Guipúzcoa, Alicante, Málaga, Murcia y A Coruña), los 2,1 millones de puestos de trabajo resultantes suponen más de dos terceras partes del total $(68,0 \%)$. En el extremo opuesto, son ocho las provincias interiores (Ávila, Cuenca, Guadalajara, Palencia, Segovia, Soria, Teruel y Zamora) que no alcanzan los 10.000 afiliados, sumando tan sólo el 1,7\% del volumen existente en España, al tiempo que otras diecisiete -igualmente interiores en su gran mayoría- tampoco alcanzan el $1 \%$ de esa cifra total (figura 1a). Se reproducen así contrastes interregionales bien conocidos, pero que ahora se observan desde una nueva perspectiva y alcanzan una intensidad incluso superior a la considerada en otros estudios (Garrido, 2002).

Tabla 2

PROVINCIAS CON MAYOR VOLUMEN DE EMPLEO EN ECONOMÍA DEL CONOCIMIENTO, 2009

\begin{tabular}{|l|r|r|r|r|r|r|r|r|}
\hline Provincias & $\begin{array}{c}\text { Número } \\
\text { afiliados }\end{array}$ & $\begin{array}{c}\text { \% } \\
\text { España }\end{array}$ & $\begin{array}{c}\text { Economía } \\
\text { conocimiento/ } \\
\text { total (\%) }\end{array}$ & $\begin{array}{c}\text { Industrias } \\
\text { alta IT } \\
\text { (\% prov. })\end{array}$ & $\begin{array}{c}\text { Servicios } \\
\text { avanzados } \\
\text { (\% prov.) }\end{array}$ & $\begin{array}{c}\text { Finanzas } \\
\text { y seguros } \\
\text { (\% prov. })\end{array}$ & $\begin{array}{c}\text { Educación } \\
\text { (\% prov.) }\end{array}$ & $\begin{array}{c}\text { Sector } \\
\text { cultural } \\
\text { (\% prov.) }\end{array}$ \\
\hline Madrid & 766.673 & 24,50 & 27,21 & 2,76 & 12,36 & 3,99 & 4,97 & 3,13 \\
Barcelona & 550.425 & 17,59 & 23,63 & 5,52 & 7,79 & 2,73 & 4,89 & 2,70 \\
Valencia & 161.914 & 5,17 & 17,24 & 3,33 & 5,75 & 2,47 & 4,21 & 1,46 \\
Sevilla & 111.663 & 3,57 & 16,17 & 2,00 & 6,09 & 2,15 & 4,42 & 1,52 \\
Vizcaya & 105.633 & 3,38 & 22,98 & 4,93 & 7,74 & 2,57 & 5,95 & 1,79 \\
Zaragoza & 85.310 & 2,73 & 21,65 & 7,93 & 5,78 & 2,54 & 4,05 & 1,35 \\
Guipúzcoa & 75.493 & 2,41 & 25,17 & 8,86 & 5,90 & 2,31 & 6,40 & 1,70 \\
Alicante & 70.749 & 2,26 & 12,80 & 1,22 & 4,63 & 2,68 & 3,17 & 1,09 \\
Málaga & 69.781 & 2,23 & 13,66 & 0,85 & 5,39 & 2,35 & 3,87 & 1,21 \\
Murcia & 65.250 & 2,09 & 12,56 & 1,86 & 3,90 & 1,87 & 3,89 & 1,04 \\
A Coruña & 65.220 & 2,08 & 15,52 & 1,90 & 6,00 & 2,36 & 3,59 & 1,67 \\
\hline
\end{tabular}

Fuente: Tesorería General de la Seguridad Social. 
Pero si bien esto ya permite apreciar algunas tendencias significativas, la economía del conocimiento constituye, en buena medida, un patrimonio urbano y es, por tanto, al descender a esta escala de análisis cuando pueden precisarse las verdaderas dimensiones de la polarización. Al utilizar como unidades espaciales de análisis las áreas urbanas definidas en el Atlas Estadístico de las Áreas Urbanas de España ${ }^{5}$ se pone de manifiesto que las de Madrid y Barcelona suman 1,3 millones de afiliados y reúnen el 40,8\% del empleo español, proporción que supera ya la mitad del total $(50,8 \%)$ si se añaden las de Valencia, Sevilla y Bilbao (tabla 3). Que tan sólo cinco áreas urbanas -que suman en conjunto 321 municipiosrepresenten unos efectivos laborales equivalentes al resto del territorio es ya buena muestra de esa selectividad en la localización, que se acentúa en el caso de las industrias y servicios culturales, donde la participación alcanza un 59,6\%, junto a los servicios avanzados a empresas $(57,7 \%)$, mientras resulta algo inferior en el resto (figura 2 ).

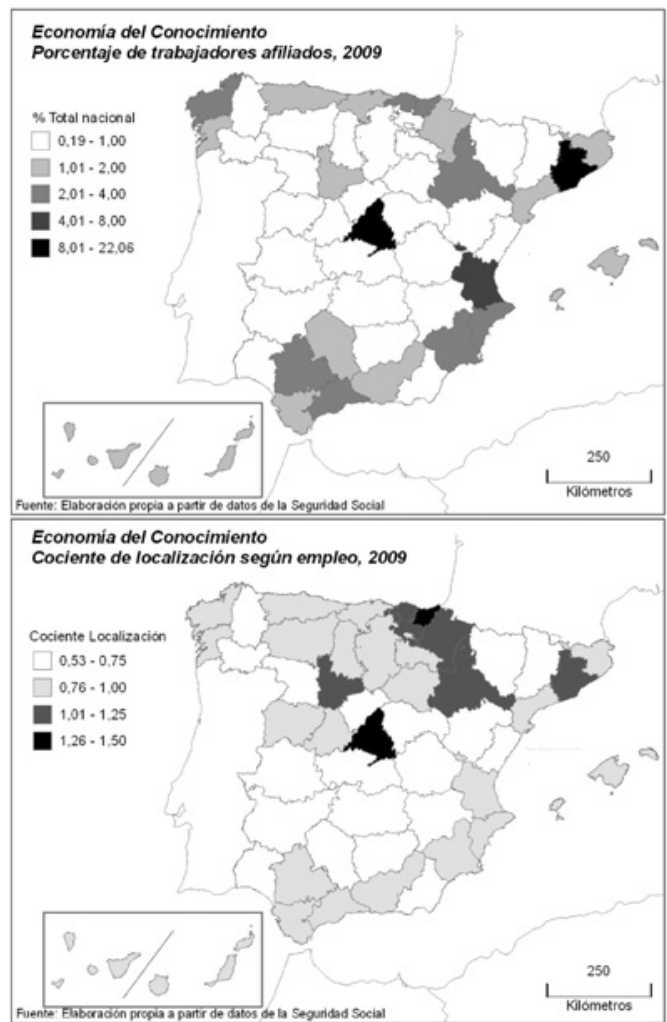

5 La primera edición, realizada por el entonces Ministerio de la Vivienda, se realizó en 2000 y existen versiones posteriores (2004 y 2006) disponibles en htp://siu.vivienda.es/portal/index.php?option=com_content\&view category \&layout=blog\&id=19\&Itemid=73\&lang=es 


\begin{tabular}{|c|c|c|c|c|c|c|c|c|c|c|c|c|c|c|c|c|c|c|c|}
\hline 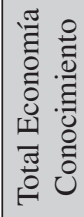 & 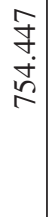 & $\begin{array}{l}\infty \\
0 \\
\text { ते } \\
\text { ñ }\end{array}$ & 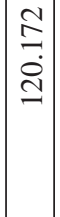 & \begin{tabular}{l}
7 \\
\multirow{2}{*}{} \\
8 \\
8
\end{tabular} & 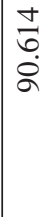 & $\begin{array}{l}1 \\
\sigma \\
\infty \\
\infty \\
n \\
-\end{array}$ & 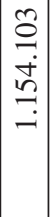 & $\left|\begin{array}{c}2 \\
\hat{2} \\
2 \\
\infty \\
n\end{array}\right|$ & 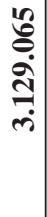 & 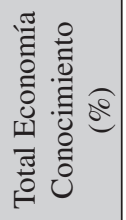 & $\begin{array}{l}\exists \\
\stackrel{d}{d}\end{array}$ & $\begin{array}{l}\tilde{\hat{\sigma}} \\
\underline{\underline{0}}\end{array}$ & \begin{tabular}{l}
\multirow{\infty}{*}{} \\
m.
\end{tabular} & $\begin{array}{l}\tilde{N} \\
\tilde{n}\end{array}$ & $\begin{array}{l}8 \\
\text { i }\end{array}$ & $\begin{array}{l}\infty \\
\stackrel{\infty}{n} \\
\stackrel{n}{n}\end{array}$ & $\left|\begin{array}{l}\infty \\
\infty \\
0 \\
0 \\
0\end{array}\right|$ & $\begin{array}{l}m \\
\tilde{\Omega} \\
\tilde{I}\end{array}$ & $\stackrel{8}{=}$ \\
\hline 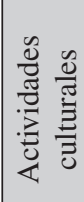 & \begin{tabular}{l}
$\exists$ \\
\multirow{2}{2}{} \\
$\dot{0}$ \\
$\infty$
\end{tabular} & 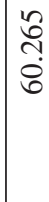 & $\left|\begin{array}{l}\stackrel{\Omega}{\alpha} \\
\grave{0}\end{array}\right|$ & $\begin{array}{l}\infty \\
\stackrel{\infty}{+} \\
\sigma\end{array}$ & 官 & 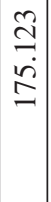 & $\mid \begin{array}{c}1 \\
\vdots \\
\vdots \\
\infty\end{array}$ & $\mid \begin{array}{c}\tilde{\infty} \\
\stackrel{\infty}{\sim} \\
\dot{m}\end{array}$ & 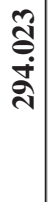 & 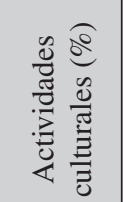 & 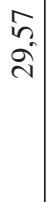 & $\mid \begin{array}{l}0 \\
n \\
\tilde{n} \\
n\end{array}$ & 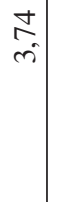 & $\begin{array}{l}\tilde{r} \\
\tilde{m}\end{array}$ & $\begin{array}{l}n \\
n \\
n\end{array}$ & 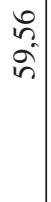 & $\left|\begin{array}{l}\tilde{b} \\
\grave{2}\end{array}\right|$ & $\mid \begin{array}{l}\infty \\
\infty \\
0 \\
-\end{array}$ & $\Xi$ \\
\hline 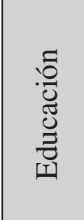 & $\begin{array}{l}\frac{-}{a} \\
\dot{n} \\
\check{2}\end{array}$ & 온 & 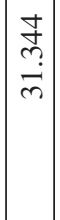 & 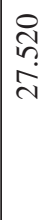 & $\begin{array}{l}0 \\
+ \\
\infty \\
+ \\
+\end{array}$ & $\begin{array}{l}\hat{D} \\
\infty \\
\dot{0} \\
\sim\end{array}$ & 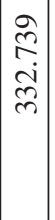 & $\mid \begin{array}{c}\overrightarrow{0} \\
\tilde{N} \\
\tilde{\infty}\end{array}$ & $\begin{array}{l}\hat{0} \\
\infty \\
\dot{T} \\
\mathbb{N}\end{array}$ & 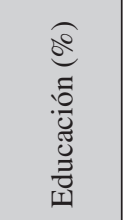 & $\begin{array}{l}\stackrel{0}{2} \\
\infty \\
\infty\end{array}$ & $\begin{array}{l}\underset{J}{J} \\
\dot{\Xi}\end{array}$ & 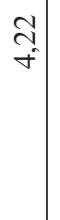 & $\frac{尺}{m}$ & $\begin{array}{c}\dot{m} \\
m \\
m\end{array}$ & $\begin{array}{l}8 \\
\dot{f}\end{array}$ & $\begin{array}{l}\curvearrowright \\
7 \\
7\end{array} \mid$ & $\vec{\beth}$ & $\Xi$ \\
\hline 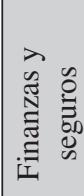 & $\begin{array}{l}\infty \\
\infty \\
\infty \\
\Xi \\
\Xi\end{array}$ & $\frac{n}{n}$ & $\left|\begin{array}{l}n \\
n \\
n \\
\check{n}\end{array}\right|$ & $\begin{array}{l}\infty \\
\stackrel{2}{\circ} \\
\stackrel{2}{2}\end{array}$ & 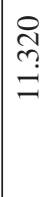 & 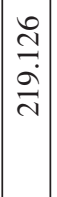 & $\left|\begin{array}{c}\infty \\
\infty \\
\infty \\
\vdots \\
\vdots \\
-\end{array}\right|$ & 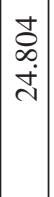 & $\begin{array}{l}\infty \\
\infty \\
\infty \\
\ddot{\gamma} \\
\ddot{\gamma}\end{array}$ & 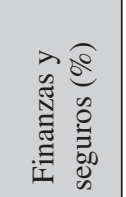 & $\begin{array}{l}\hat{b} \\
\dot{\imath}\end{array}$ & 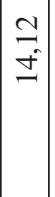 & $\vec{\nabla}$ & $\frac{a}{m}$ & $\begin{array}{l}0 \\
8 \\
i\end{array}$ & $\left|\begin{array}{l}\infty \\
1 \\
1 \\
0 \\
n\end{array}\right|$ & $\begin{array}{l}2 \\
\delta \\
f \\
f\end{array} \mid$ & $\begin{array}{l}9 \\
0 \\
\text { in }\end{array}$ & $\Xi$ \\
\hline 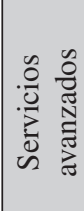 & \begin{tabular}{l}
$\checkmark$ \\
$\delta$ \\
$m$ \\
\multirow{J}{*}{} \\
$m$
\end{tabular} & $\begin{array}{l}- \\
\dot{+} \\
\dot{I} \\
\beth\end{array}$ & $\left|\begin{array}{c}0 \\
0 \\
\dot{f} \\
\dot{f}\end{array}\right|$ & $\underset{\text { m }}{\text { 守 }}$ & $\begin{array}{l}\hat{+} \\
\hat{i} \\
\text { r. }\end{array}$ & 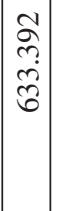 & 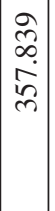 & $\mid \begin{array}{c}8 \\
0 \\
\vdots \\
0 \\
0\end{array}$ & 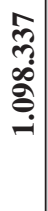 & 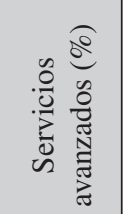 & $\begin{array}{l}m \\
m \\
m\end{array}$ & $\begin{array}{l}\infty \\
\infty \\
2\end{array}$ & $\begin{array}{l}\overrightarrow{0} \\
\dot{f}\end{array}$ & $\stackrel{m}{\tilde{f}}$ & $\begin{array}{c}8 \\
\dot{\sigma}\end{array}$ & $\begin{array}{c}\hat{6} \\
\hat{n}\end{array}$ & $\left|\begin{array}{c}\infty \\
n \\
n \\
n \\
n\end{array}\right|$ & $\begin{array}{l}n \\
a \\
a\end{array} \mid$ & छ \\
\hline 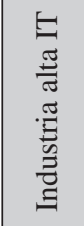 & $\begin{array}{c}0 \\
7 \\
\dot{\gamma} \\
\sim\end{array}$ & $\begin{array}{l}n \\
\tilde{n} \\
\varrho\end{array}$ & $\begin{array}{c}\hat{0} \\
m \\
\tilde{n} \\
2\end{array} \mid$ & $\underset{\infty}{\stackrel{\infty}{c}}$ & $\begin{array}{l}\hat{\delta} \\
\dot{\delta} \\
\dot{+}\end{array}$ & 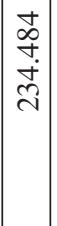 & $\mid \begin{array}{c}0 \\
0 \\
n \\
\dot{\infty} \\
\infty \\
-\end{array}$ & $\mid \begin{array}{c}0 \\
0 \\
0 \\
\grave{2}\end{array}$ & $\begin{array}{l}0 \\
0 \\
\infty \\
10 \\
i n\end{array}$ & 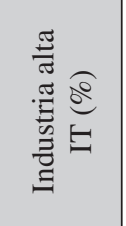 & $\vec{n}$ & $\stackrel{\stackrel{T}{\mathcal{T}}}{\stackrel{\sim}{\sim}}$ & $\begin{array}{l}\infty \\
m \\
i\end{array}$ & $\frac{\infty}{i}$ & $\begin{array}{c}\tilde{n} \\
\tilde{n}\end{array}$ & $\begin{array}{c}\mathcal{J} \\
\mathcal{f} \\
\mathcal{f}\end{array} \mid$ & $\mid \begin{array}{c}\hat{b} \\
\hat{m} \\
\end{array}$ & $\begin{array}{l}\vec{a} \\
\vec{d}\end{array}$ & 응 \\
\hline
\end{tabular}

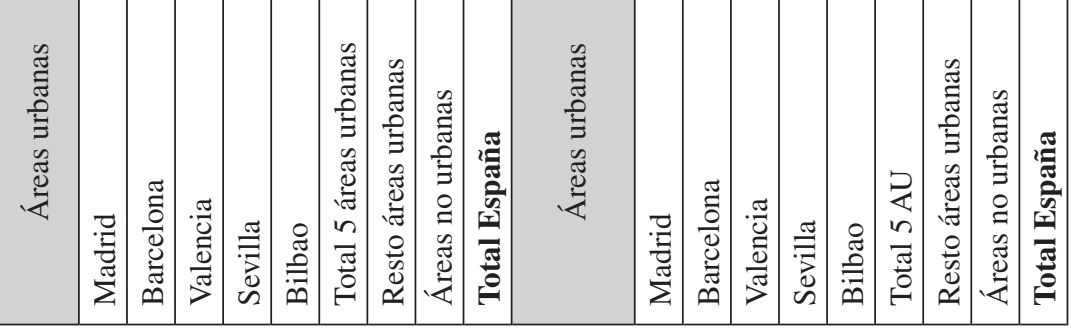


Si se desciende en la jerarquía urbana, otro dato que refuerza la misma conclusión es que son apenas 81 las áreas urbanas (de las 851 existentes) en donde se supera el millar de afiliados, pero en ellas se localiza hasta el $87,6 \%$ del total. Por el contrario, en las áreas consideradas rurales apenas se localizan uno de cada ocho empleos, destacando tan sólo su participación en el caso de las actividades industriales (24,9\% del total), que confirman tendencias deslocalizadoras bastante más acusadas. La atracción que ejercen las aglomeraciones metropolitanas queda así fuera de toda duda, como exponente de las economías de localización y urbanización ya mencionadas. Pero un proceso de aglomeración como el observado exige recurrir también al efecto ejercido por otros recursos intangibles, tales como el capital simbólico acumulado en ciertos espacios centrales de las metrópolis como son los distritos de negocios, la proximidad a los centros de decisión e, incluso, grandes actuaciones públicas de renovación urbana en áreas degradadas que utilizan este tipo de actividades como elemento de revalorización y dinamización.

No obstante, si bien las grandes ciudades (más de 250.000 habs.) reúnen 1,4 millones de empleos en estas actividades (44,2\% del total), no debe ignorarse la presencia de numerosas ciudades de tamaño intermedio que han logrado cierta especialización en algunas de ellas. Así, las comprendidas entre 50.000 y 250.000 habs. contabilizan ya 965.603 afiliados (30,9\%), junto a otros 496.082 en las de 10.000 a 50.000 (15,8\%). La inclusión de Pamplona, San Sebastián, Vitoria, Córdoba o Girona entre las 25 áreas urbanas con mayor volumen de trabajadores, bastante por encima de su rango poblacional, es otra llamada de atención sobre la necesidad de no excluir a priori a este tipo de ciudades (Romeiro y Méndez, 2008).

Figura 2

EMPLEO EN ACTIVIDADES INTENSIVAS EN CONOCIMIENTO POR ÁREAS URBANAS

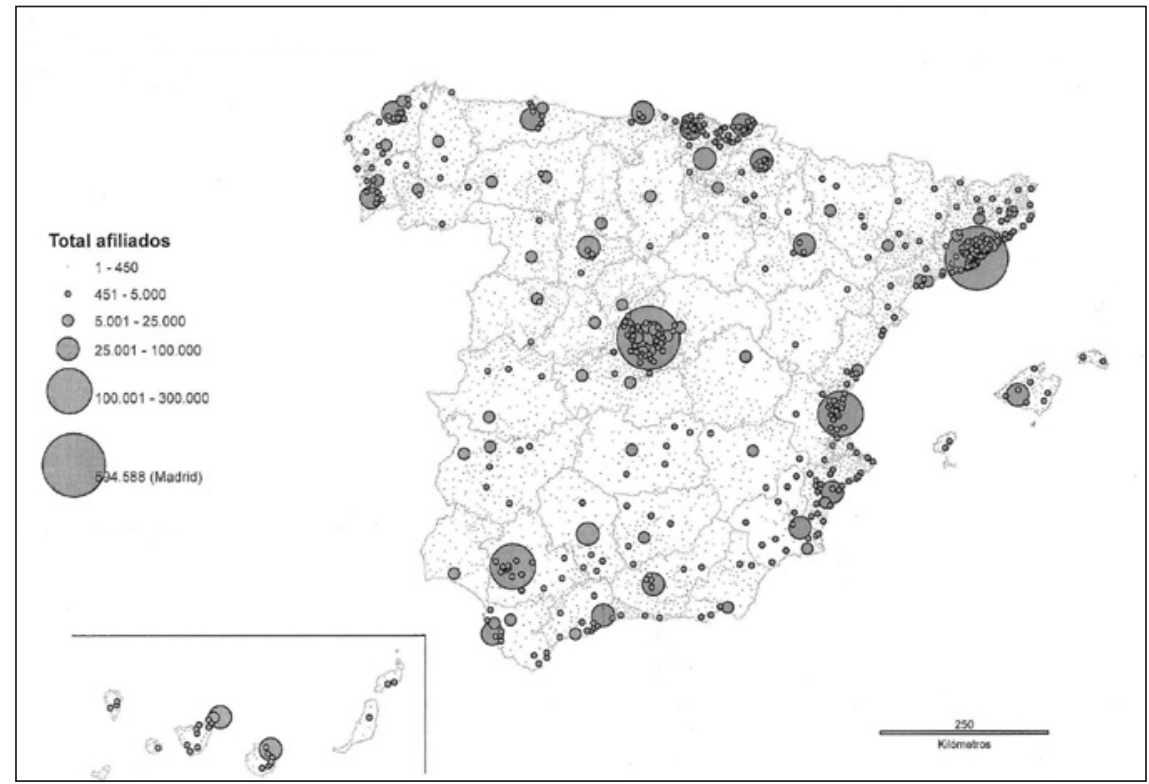

Fuente: Tesorería General de la Seguridad Social. 
Imagen complementaria es la relativa a la desigual especialización de los territorios en economía del conocimiento, cualquiera que sea su volumen absoluto de empleo. También en este caso la provincia de Madrid (27,2\%) se sitúa por encima del resto, pero la segunda posición corresponde ahora a Guipúzcoa $(25,2 \%)$, donde estas actividades superan en importancia relativa a Barcelona $(23,6 \%)$, con Vizcaya $(23,0 \%)$, Navarra $(22,7 \%)$, Zaragoza $(21,6 \%)$, Álava $(21,3 \%)$ y Valladolid (20,9\%) en valores próximos. De nuevo en las regiones interiores y el sur peninsular son varias las provincias (Almería, Cáceres, Cuenca, Huelva, Jaén, Lugo, Teruel) donde la ocupación en estos sectores resulta testimonial, sin alcanzar siquiera un $10 \%$ del total de afiliados, por lo que puede hablarse de una exclusión efectiva. El uso de cocientes de localización, que relacionan estas proporciones con el promedio español (18\%) y definen el grado de especialización relativa según los valores sean superiores o inferiores a la unidad, muestra con claridad las principales regularidades espaciales (figura 1b). Entre el cociente superior (Madrid $=1,51)$ e inferior $($ Cuenca $=0,41)$ la distribución confirma que los tradicionales polos de conocimiento de Madrid y Barcelona se ven acompañados por los del País Vasco y se prolongan a través del valle del Ebro, alcanzado también a alguna otra provincia como Valladolid, frente a su limitada presencia en los ejes Atlántico y Mediterráneo, los territorios interiores y los archipiélagos, donde el crecimiento económico se basó en otro tipo de actividades intensivas en mano de obra y/o capital.

Pero es de nuevo a escala urbana donde se aprecia mejor la diversidad de perfiles locales según la importancia relativa que alcanzan en cada caso los diferentes sectores intensivos en conocimiento. Así, por ejemplo, en el área de Madrid existe un neto predominio de los servicios avanzados a las empresas (344.302 afiliados), coherente con su creciente inserción internacional (Sánchez Moral, Calatrava y Melero, 2008), mientras en Barcelona las industrias de alta intensidad tecnológica aún suponen 119.517 afiliados (tabla 3). No obstante, el resultado más significativo se obtiene al aplicar cocientes de localización a las treinta y ocho áreas que superan los 10.000 afiliados (81,6\% del total), empleando en esta ocasión un método de representación gráfico que sustituye los valores numéricos por una gama de color, con intensidad asociada al grado de especialización en cada tipo de actividad (figura 3).

Figura 3

ESPECIALIZACIÓN DE LAS PRINCIPALES ÁREAS URBANAS EN ACTIVIDADES INTENSIVAS EN CONOCIMIENTO

\begin{tabular}{|l|l|l|l|l|l|}
\hline \multicolumn{1}{|c|}{ Áreas Urbanas } & $\begin{array}{c}\text { Industria } \\
\text { alta/media- } \\
\text { alta IT }\end{array}$ & $\begin{array}{c}\text { Servicios } \\
\text { avanzados } \\
\text { empresas }\end{array}$ & $\begin{array}{c}\text { Finanzas y } \\
\text { seguros }\end{array}$ & Educación & $\begin{array}{c}\text { Industrias } \\
\text { y servicios } \\
\text { culturales }\end{array}$ \\
\hline Madrid & & & & & \\
\hline Barcelona & & & & & \\
\hline Valencia & & & & & \\
\hline Sevilla & & & & & \\
\hline Bilbao & & & & & \\
\hline Zaragoza & & & & & \\
\hline
\end{tabular}




\begin{tabular}{|c|c|c|c|c|c|}
\hline Áreas Urbanas & $\begin{array}{l}\text { Industria } \\
\text { alta/media- } \\
\text { alta IT }\end{array}$ & $\begin{array}{c}\text { Servicios } \\
\text { avanzados } \\
\text { empresas }\end{array}$ & $\begin{array}{c}\text { Finanzas y } \\
\text { seguros }\end{array}$ & Educación & $\begin{array}{l}\text { Industrias } \\
\text { y servicios } \\
\text { culturales }\end{array}$ \\
\hline \multicolumn{6}{|l|}{ Málaga } \\
\hline \multicolumn{6}{|l|}{ Vigo - Pontevedra } \\
\hline \multicolumn{6}{|l|}{ Área Central Asturias } \\
\hline \multicolumn{6}{|l|}{ Pamplona } \\
\hline \multicolumn{6}{|l|}{ Murcia } \\
\hline \multicolumn{6}{|l|}{ San Sebastián } \\
\hline \multicolumn{6}{|l|}{ Alicante - Elche } \\
\hline \multicolumn{6}{|l|}{ Valladolid } \\
\hline \multicolumn{6}{|l|}{ Palma de Mallorca } \\
\hline \multicolumn{6}{|l|}{ A Coruña } \\
\hline \multicolumn{6}{|l|}{ Bahía de Cádiz } \\
\hline \multicolumn{6}{|l|}{ Granada } \\
\hline \multicolumn{6}{|l|}{$\begin{array}{l}\text { Las Palmas Gran } \\
\text { Canaria }\end{array}$} \\
\hline \multicolumn{6}{|l|}{ Sta.Cruz Tenerife } \\
\hline \multicolumn{6}{|l|}{ Tarragona - Reus } \\
\hline \multicolumn{6}{|l|}{ Vitoria } \\
\hline \multicolumn{6}{|l|}{ Santander - Torrelavega } \\
\hline \multicolumn{6}{|l|}{ Córdoba } \\
\hline \multicolumn{6}{|l|}{ Girona } \\
\hline \multicolumn{6}{|l|}{ Castellón de la Plana } \\
\hline \multicolumn{6}{|l|}{ Burgos } \\
\hline \multicolumn{6}{|l|}{ Almería } \\
\hline \multicolumn{6}{|l|}{ Salamanca } \\
\hline \multicolumn{6}{|l|}{ León } \\
\hline \multicolumn{6}{|l|}{ Santiago Compostela } \\
\hline Lleida & & & & & \\
\hline
\end{tabular}




\begin{tabular}{|l|l|l|l|l|l|}
\hline \multicolumn{1}{|c|}{ Áreas Urbanas } & $\begin{array}{c}\text { Industria } \\
\text { alta/media- } \\
\text { alta IT }\end{array}$ & $\begin{array}{c}\text { Servicios } \\
\text { avanzados } \\
\text { empresas }\end{array}$ & $\begin{array}{c}\text { Finanzas y } \\
\text { seguros }\end{array}$ & Educación & $\begin{array}{c}\text { Industrias } \\
\text { y servicios } \\
\text { culturales }\end{array}$ \\
\hline Logroño & & & & & \\
\hline Huelva & & & & & \\
\hline Toledo & & & & & \\
\hline Jaén & & & & & \\
\hline Albacete & & & & & \\
\hline Badajoz & & & & & \\
\hline
\end{tabular}

Fuente: Tesorería General de la Seguridad Social.

Una parte de las ciudades con tradición industrial de los ejes Atlántico y del Ebro han mantenido su especialización en sectores intensivos en tecnología, con Vigo-Pontevedra, Vitoria, Pamplona y Zaragoza como casos más destacados. Por el contrario, otros antiguos centros fabriles como los de Bilbao, San Sebastián o el Área Central de Asturias han perdido esa especialización tras un proceso de reconversión que orientó su economía hacia los servicios, o bien mantienen una base manufacturera dominada por ramas ajenas a las aquí consideradas. En el eje Mediterráneo esa presencia de la industria resulta, en cambio, menos importante, pero tanto el área de Barcelona como las de Tarragona-Reus y Castellón mantienen cocientes superiores a la unidad, lo que en el interior peninsular tan sólo ocurre en Burgos y Valladolid ante la hipertrofia del sector terciario en Madrid. En algunos de estos casos se comprueba, por tanto, que la industria no es sólo parte de su pasado, sino que puede ser aún la base de economías competitivas que determinados discursos sobre la sociedad del conocimiento o la creatividad han ignorado demasiado a menudo.

Los servicios avanzados a empresas son, con diferencia, la actividad que genera más empleo y está presente de forma destacada en todas las áreas urbanas analizadas, si bien tiende a concentrarse en los niveles superiores de la jerarquía, allí donde a las empresas con clientela de proximidad se añaden las que operan en mercados globales. Por esa razón, cinco de las siete mayores están especializadas en ellos y sólo la de Madrid representa casi una tercera parte $(31,3 \%)$ de todos los afiliados que se contabilizan en España, duplicando el peso relativo de Barcelona (15,9\%) y multiplicando por ocho el de Valencia $(4,0 \%)$.

Pero aún es mayor la concentración metropolitana del sector cultural, pues las áreas de Madrid y Barcelona concentran la misma cantidad de empleos en estas actividades que el resto del territorio español, al atraer a buena parte de las industrias y servicios más importantes del sector privado (cine, televisión, radio, industria musical, editoriales, videojuegos, artes escénicas...), junto a grandes equipamientos públicos (museos, archivos, bibliotecas...). El fuerte sesgo que imprime esa estructura bipolar justifica el muy escaso número de áreas urbanas especializadas, pues a éstas sólo se añaden unas pocas 
que cuentan con un importante patrimonio cultural y un amplio desarrollo de actividades derivadas, en gran medida promovidas por el sector público (Santiago de Compostela, Toledo, Logroño).

En cambio, tanto el sector financiero y de seguros como el educativo son los que presentan una distribución más dispersa, pues si bien las entidades de mayor rango (sedes bancarias y de grandes firmas de seguros, universidades...) aparecen sólo en las principales ciudades de cada región, el resto (agencias y oficinas, centros de enseñanza primaria, secundaria o formación profesional) se distribuye en ciudades pequeñas o de tamaño medio en relación con el reparto de la población. Por ese motivo son bastante numerosas las áreas urbanas especializadas tan sólo en estas actividades (16 de las 38), con cocientes que pueden resultar elevados cuando escasean aquellas otras con una localización más selectiva.

\section{ECONOMÍA DEL CONOCIMIENTO Y DESARROLLO TERRITORIAL: PRINCIPALES RELACIO- NES Y DEBATES.}

Además de analizar las tendencias dominantes en la localización del empleo en actividades intensivas en conocimiento, el artículo pretende revisar su posible asociación espacial con diversas características económicas y sociolaborales de los territorios. Para ello se elaboró una matriz de datos con información sobre el peso de cada provincia en el empleo total español en economía del conocimiento, su importancia relativa en el empleo provincial y la alcanzada por cada una de las actividades que la constituyen. Esas siete variables se confrontaron con tres relativas al tamaño provincial en términos de población, empleo y PIB, así como con otras siete utilizadas de forma habitual cuando se analizan la competitividad o el desarrollo socioeconómico de los territorios (tabla 4).

Tabla 4

INDICADORES PROVINCIALES DE ECONOMÍA DEL CONOCIMIENTO Y DESARROLLO TERRITORIAL, 2009

\begin{tabular}{|c|c|}
\hline $\begin{array}{l}\text { A } \\
\text { Economía del } \\
\text { conocimiento }\end{array}$ & $\begin{array}{l}\text { 1. Empleo en economía del conocimiento (\% total España) } \\
\text { 2. Empleo en economía del conocimiento (\% empleo provincia) } \\
\text { 3. Empleo en industrias alta/media-alta intensidad tecnológica (\% } \\
\text { empleo provincia) } \\
\text { 4. Empleo en servicios avanzados a empresas ( } \% \text { empleo provincia) } \\
\text { 5. Empleo en actividades financieras y de seguros (\% empleo } \\
\text { provincia) } \\
\text { 6. Empleo en actividades educativas ( } \% \text { empleo provincia) } \\
\text { 7. Empleo en industrias y servicios culturales (\% empleo provincia) }\end{array}$ \\
\hline $\begin{array}{c}\text { B } \\
\text { Tamaño }\end{array}$ & $\begin{array}{l}\text { 8. Población provincial ( } \% \text { total España) } \\
\text { 9. Afiliados a la Seguridad Social ( } \% \text { total España) } \\
\text { 10. Producto interior bruto ( } \% \text { total España) }\end{array}$ \\
\hline
\end{tabular}




\begin{tabular}{|c|l|}
\hline & $\begin{array}{l}\text { 11. Producto interior bruto por habitante (miles de euros) } \\
\text { 12. Productividad media por empleo (miles de euros) }\end{array}$ \\
Competitividad & 13. Exportaciones por empleo (miles de euros) \\
14. Renta bruta por habitante (miles de euros) \\
\end{tabular}

Fuente: Tesorería General de la Seguridad Social, Instituto Nacional de Estadística e Instituto Nacional de Empleo.

Una primera etapa en el análisis realizado consistió en calcular los coeficientes de correlación de Pearson entre estos diecisiete pares de variables para identificar el grado de asociación espacial y su sentido positivo o negativo (tabla 5). Aunque los resultados podrían dar pie a un comentario más pormenorizado, aquí se fijará la atención tan sólo en aquellos aspectos que más aportan al debate sobre el comportamiento espacial de las actividades intensivas en conocimiento y su posible asociación con otras características del territorio:

- El volumen de empleo en estas actividades está directamente relacionado con los de población, empleo o producción, al derivarse, en buena medida, del tamaño provincial estimado a partir de esos indicadores con los que existe una muy elevada correlación positiva, siempre superior a 0,960. Se confirma así que el factor aglomeración es fundamental para entender el desigual reparto de sus efectivos provinciales.

- Su importancia relativa en el empleo provincial guarda también cierta relación con esos tres indicadores (coeficientes entre 0,544 y 0,599), pero es bastante superior la existente con otros como el PIB por habitante $(r=0,764)$, la productividad por empleo $(r=0,636)$ $\mathrm{y}$, sobre todo, la presencia de población con estudios superiores $(\mathrm{r}=0,864)$. En otras palabras, las provincias con una economía más intensiva en conocimiento y más capital humano se corresponden con las que muestran mayor eficiencia productiva y niveles superiores de ingresos, con independencia de su volumen total de población, ocupación o producción.

- Si se consideran por separado los cinco grupos de actividades analizadas pueden diferenciarse tres tipos de comportamientos. La proporción de empleo en servicios avanzados muestra una alta correlación positiva con la presencia del sector financiero y de seguros $(\mathrm{r}=0,772)$ y, más aún, con la del sector cultural $(\mathrm{r}=0,929)$, al tiempo que también lo es la asociación con la propia especialización provincial en economía del conocimiento considerada en su conjunto $(r=0,839)$. Esto puede justificar que a menudo sean éstas las actividades más consideradas en la literatura sobre ciudades del conocimiento (Winden, Berg y Pol., 2007). Por su parte, el sector educativo sólo muestra una correlación positiva con los servicios avanzados $(r=0,548)$ y las actividades culturales $(r=0,522)$, pero al tratarse en buena medida de un servicio público responde a lógicas diferentes y eso se traduce en una distribución más equilibrada. 


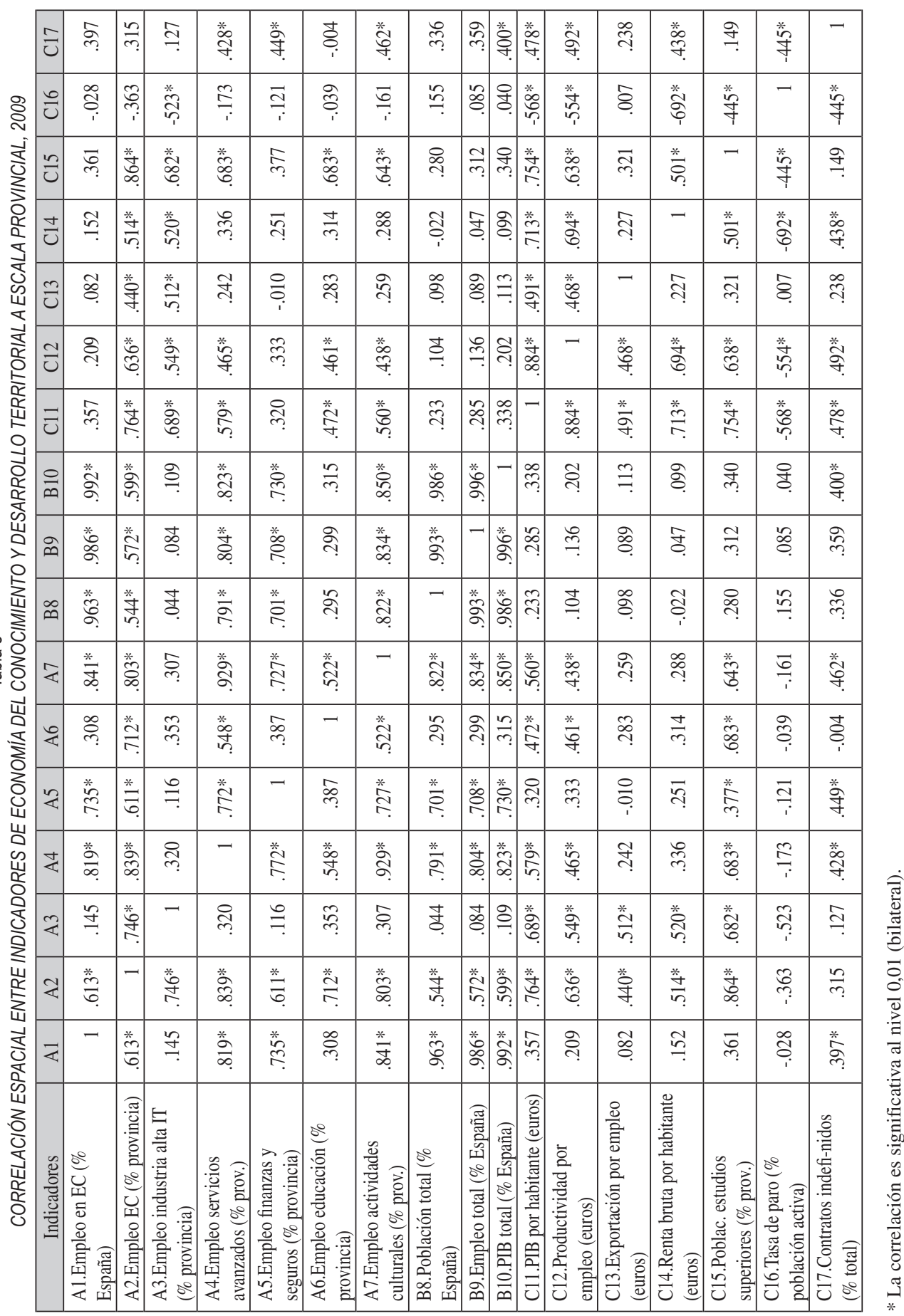


- Muy distinto es, en cambio, el comportamiento espacial de las ramas industriales intensivas en el uso de conocimiento y que realizan un mayor esfuerzo innovador. Se comprueba aquí que parecen poco relacionadas en términos de proximidad física con las restantes actividades de servicios, lo que supone estrategias de localización más relacionadas con recursos como el capital humano altamente cualificado $(r=0,682)$, así como con la trayectoria de determinados territorios en donde se ha generado un saber hacer acumulativo y se ha desarrollado un marco institucional encargado de alimentarlo.

Pero es al correlacionar la importancia de la economía del conocimiento con diversos indicadores de competitividad y desarrollo socioeconómico cuando los resultados ponen en cuestión afirmaciones frecuentes en una parte de la bibliografía sobre esta temática:

- El empleo provincial en servicios avanzados muestra una moderada asociación espacial, tanto con un indicador de capacidad de consumo como la renta bruta por habitante ( $\mathrm{r}=$ 0,336), como con otros de eficiencia y esfuerzo innovador tales como la productividad del trabajo $(r=0,465)$ o la capacidad exportadora $(r=0,242)$. Esos coeficientes resultan similares a los del sector cultural, pero son, incluso, bastante inferiores en los casos del sector financiero o del educativo. Puede, por tanto, deducirse que los servicios intensivos en conocimiento, concentrados en las provincias más pobladas, con mayor volumen de empleo, producción y capital humano altamente formado, no se asocian necesariamente a una economía más eficiente y mejor posicionada frente a los actuales retos competitivos, al existir otras claves explicativas de esto último ajenas a las aquí consideradas.

- De nuevo en este caso, las industrias intensivas en tecnología ofrecen una imagen netamente distinta al presentar una correlación significativa, tanto con el PIB $(r=0,689)$ y la renta por habitante $(\mathrm{r}=0,520)$, como con la productividad $(\mathrm{r}=0,549)$, capacidad exportadora $(r=0,512)$ o presencia de titulados superiores $(r=0,682)$. Aunque se está lejos de asociaciones lineales, estos valores estadísticos alertan sobre lo inadecuado de determinados discursos postindustriales que han ignorado la capacidad de una parte de las actividades y empresas manufactureras para incrementar la competitividad económica de determinados territorios, generando resultados en forma de innovaciones y ofreciendo una vía específica de acceso a esa tan deseada economía del conocimiento.

- Por el contrario, la importancia alcanzada por ésta en el empleo provincial apenas guarda relación con las tasas de paro $(r=-0,363)$, al ser escaso el efecto que una mayor presencia de tales actividades ejerce sobre su reducción. Tan sólo en el caso de la industria esa correlación de sentido negativo llega a resultar significativa $(r=-0,523)$, lo que parece afianzar el argumento anterior. Menor aún es su asociación espacial con la presencia de contratos indefinidos entre los firmados en los tres últimos años $(r=0,315)$. Se pone así en cuestión que un aumento de los sectores más intensivos en conocimiento o una mayor presencia de titulados superiores en la población activa $(r=0,15)$ conlleve necesariamente mayor estabilidad en la contratación, aspecto mucho más influido por la regulación del mercado laboral en cada sector que por este otro tipo de factores. Mayor cantidad de conocimiento en el trabajo y calidad del empleo son, pues, objetivos sociales movilizadores, pero no se derivan el uno del otro de forma espontánea.

En una segunda etapa, el análisis intentó sintetizar ese elevado número de variables en otro más reducido que agrupase aquellas altamente correlacionadas y permitiese posicionar a las provincias según sus características. Para ello se utilizó un análisis factorial mediante 
componentes principales, realizado primero para cada uno de los tres bloques de variables ya comentados y después de forma conjunta.

Según refleja la tabla 6 , los indicadores de economía del conocimiento quedan resumidos en un total de tres componentes, que explican el 92,65\% de la varianza. El primero agrupa los servicios intensivos en conocimiento junto al volumen total de empleo y se diferencia de un segundo componente constituido por las actividades industriales y de un tercero que tan sólo incluye la educación, localizada de manera específica.

Tabla 6

MATRIZ DE COMPONENTES ROTADOS: ECONOMÍA DEL CONOCIMIENTO

\begin{tabular}{|l|r|r|r|}
\hline \multicolumn{1}{|c|}{ Indicadores } & Componente & \multicolumn{1}{c|}{} \\
\cline { 2 - 4 } & 1 & 2 & 3 \\
\hline \% Empleo en economía del conocimiento / España & .937 & & \\
\hline \% Actividades culturales / total & .876 & & \\
\hline \% Servicios avanzados a empresas / total & .873 & & .324 \\
\hline \% Finanzas y seguros / total & .861 & & \\
\hline \% Industria de alta intensidad tecnológica / total & & .984 & \\
\hline \% Economía del conocimiento /empleo total & .588 & .660 & .465 \\
\hline \% Educación / total & & & .943 \\
\hline
\end{tabular}

Método de rotación: Normalización Varimax con Kaiser.

Por su parte, las tres variables que miden el tamaño provincial en términos de concentración de la población, el empleo o la producción pueden resumirse en un único componente que explica hasta el 99,45\% de la varianza. Finalmente, las variables socioeconómicas muestran tendencias más dispersas pero que quedan bien resumidas en un total de tres componentes, que explican el $85,91 \%$ de la varianza: el primero corresponde a los que pueden considerarse como indicadores de potencial y competitividad económica, el segundo se relaciona con las condiciones laborales, mientras la exportación muestra un comportamiento netamente diferenciado (tabla 7).

Tabla 7

MATRIZ DE COMPONENTES ROTADOS: CONDICIONES SOCIOECONÓMICAS

\begin{tabular}{|l|c|c|c|}
\hline \multirow{2}{*}{ Indicadores } & \multicolumn{3}{|c|}{ Componente } \\
\cline { 2 - 4 } & 1 & 2 & 3 \\
\hline \% población estudios superiores & .871 & & \\
\hline PIB / habitante (miles $€$ ) & .822 & & \\
\hline Renta bruta/ habitante (miles $€$ ) & .760 & .430 & \\
\hline Productividad/ empleo (miles $€$ ) & .755 & & \\
\hline Tasa de paro (\%) & -.719 &. .470 & \\
\hline$\%$ Contratos indefinidos/ total & & .921 & \\
\hline Exportación/ empleo (miles $€$ ) & & & .924 \\
\hline
\end{tabular}

Método de rotación: Normalización Varimax con Kaiser. 
Tras sintetizar las diecisiete variables iniciales en esos siete componentes, se calcularon de nuevo los coeficientes de correlación entre los mismos y se repitió el análisis factorial, pudiendo así extraer un total de cuatro componentes, que explican el 87,97\% de la varianza y que se corresponden con los identificados en la matriz de componentes rotados correspondiente (tabla 8). Se aprecia así que la presencia de servicios intensivos en conocimiento se asocia de forma directa al tamaño poblacional, mientras que son las industrias con mayor intensidad tecnológica las que lo hacen con los indicadores de potencial y competitividad económica. Por su parte, la estabilidad en el empleo se relaciona poco con todo lo anterior, mientras la capacidad exportadora también responde a otro tipo de razones y no se asocia con ninguna variable analizada.

Tabla 8

MATRIZ DE COMPONENTES ROTADOS: TIPOS DE COMPORTAMIENTO ESPACIAL

\begin{tabular}{|c|c|c|c|c|}
\hline & \multicolumn{4}{|c|}{ Componente } \\
\hline & 1 & 2 & 3 & 4 \\
\hline Servicios intensivos en conocimiento & .977 & & & \\
\hline Tamaño provincial & .959 & & & \\
\hline Potencial económico y competitividad & & .920 & & \\
\hline Industrias alta y media-alta IT & & .879 & & .305 \\
\hline Educación & & & .846 & \\
\hline Estabilidad en el empleo & & & -.758 & \\
\hline Capacidad exportadora & & & & .974 \\
\hline
\end{tabular}

Método de rotación: Normalización Varimax con Kaiser.

Al representar con diagramas de dispersión la correlación espacial entre esos pares de componentes mediante las puntuaciones factoriales alcanzadas por cada provincia, se deducen algunas conclusiones adicionales de interés en el plano territorial (figura 4).

Así, la presencia de industrias de alta y media-alta intensidad tecnológica se asocia de modo muy significativo con los indicadores de potencial y competitividad económica. En ese sentido, las provincias con puntuaciones factoriales más elevadas en ambos componentes corresponden a las del País Vasco, que constituyen un núcleo bien definido que se prolonga por Navarra, Rioja y Zaragoza a lo largo del valle del Ebro, Burgos y Valladolid hacia el interior de Castilla, así como Cantabria y Asturias hacia el eje Atlántico. En el extremo opuesto predominan, en cambio, las provincias mediterráneas (Málaga, Alicante, Almería, Murcia, Granada), otras andaluzas (Huelva, Cádiz, Jaén), insulares e interiores (Cáceres, Badajoz, Albacete, Toledo, Ávila, Zamora, Lugo, Ourense...), todas con valores negativos. En el caso de Madrid, su potencial y competitividad económica superan de forma nítida la importancia actual de su base industrial, mientras en Barcelona ocurre lo contrario como reflejo de sus distintas trayectorias.

Por su parte, la distribución de los servicios intensivos en conocimiento aparece aún más fuertemente asociada al volumen de población, empleo y producción de las provincias. Junto a Madrid y Barcelona, muy por encima del resto, las puntuaciones factoriales más altas 
corresponden, por tanto, a aquellas que albergan las principales aglomeraciones metropolitanas (Valencia, Sevilla, Vizcaya, Alicante, Málaga...). Por su parte, los valores más negativos en ambos ejes identifican a provincias interiores de las dos Castillas (Soria, Palencia, Salamanca, Segovia, Zamora, Cuenca...) y Extremadura, con predominio de servicios de distribución tradicionales y déficit de servicios especializados.

Por último, se incluyó también el diagrama que refleja la relación existente entre la presencia de este mismo tipo de servicios intensivos en conocimiento con la estabilidad en el empleo (tasa de paro y contratos indefinidos), que pone en evidencia una absoluta dispersión de resultados. Las provincias con valores extremos en cuanto a su situación laboral más favorable (Girona, Tarragona, Lleida, Lugo, Ourense...) o más precaria (Córdoba, Granada, Jaén, Cádiz, Huelva...) presentan niveles de servicios muy similares, con puntuaciones factoriales próximas a cero en todos los casos, confirmando lo inadecuado de ciertos supuestos simplificadores que pretenden asociar ambos aspectos, sin considerar la mayor influencia de otro tipo de factores sobre la evolución de los mercados de trabajo.

Figura 4

DIFERENCIAS PROVINCIALES SEGÚN COMPORTAMIENTO ESPACIAL EN ECONOMÍA DEL CONOCIMIENTO

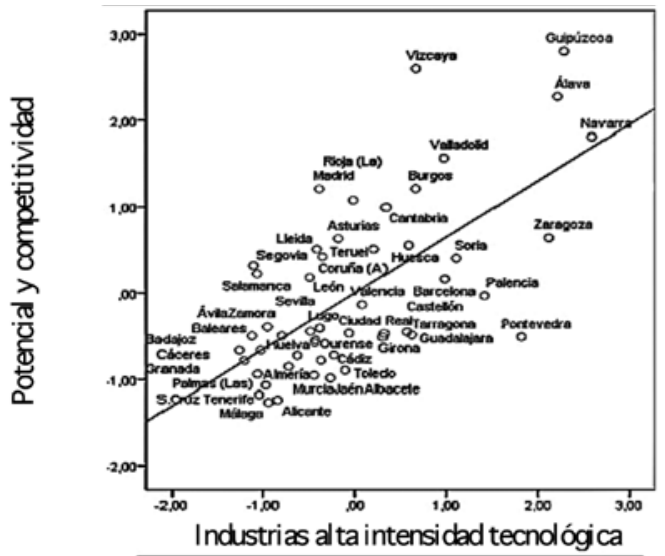

$R^{2}$ Lineal $=0,425$

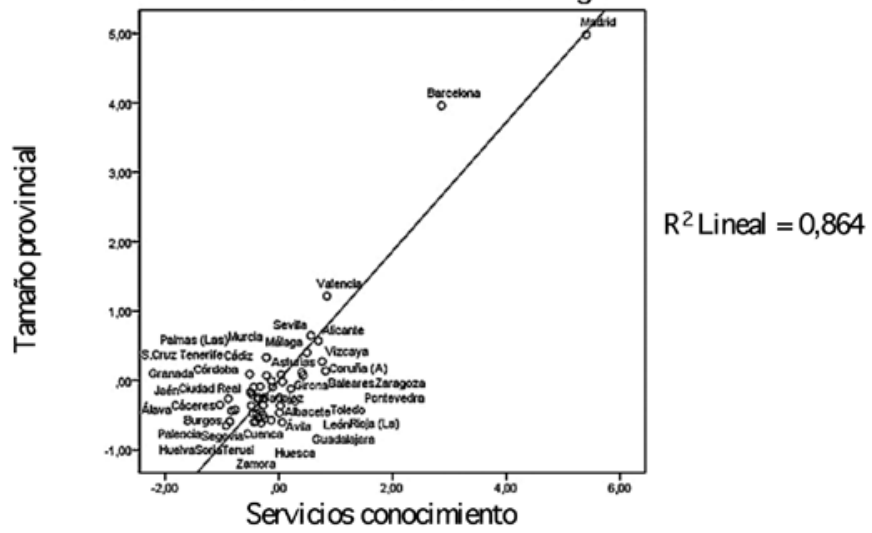




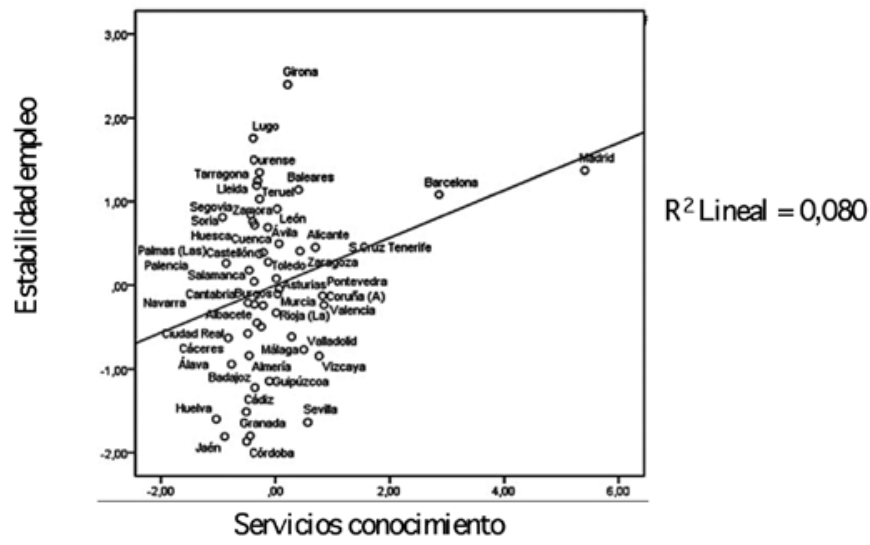

\section{CONCLUSIONES}

La última década ha conocido en España la sucesión de dos periodos marcados respectivamente por una intensa creación y destrucción de empleos, con el inicio de la crisis financiera e inmobiliaria en 2008 como momento de ruptura. No obstante, para comprender y valorar mejor los cambios estructurales subyacentes, resultan útiles visiones transversales como la que propone el concepto de economía del conocimiento, al integrar industrias y servicios con una elevada proporción de empleo cualificado, que llevan a cabo un importante esfuerzo de innovación y generan bienes o servicios de alto valor añadido. Al considerar su situación en 2009 se comprueba que dan empleo a poco más de tres millones de trabajadores, algo menos de una quinta parte del total, aunque su volumen aumentó en medio millón desde el inicio de la década. Elevar esa proporción -además de mejorar también la eficiencia empresarial y la calidad del empleo en las restantes actividades- constituye uno de los retos actuales para la economía española, por lo que estudiar sus características, estructura y distribución territorial, la geometría de los flujos de conocimiento o los frenos a su expansión, supone una línea de investigación útil en geografía económica.

Pese a tratarse en su mayor parte de actividades que manejan recursos intangibles y obtienen productos inmateriales, lo que les dota de una elevada libertad potencial de localización, su distribución está fuertemente dominada por la concentración, cualquiera que sea la escala considerada. Si se toman las provincias como referencia, Madrid y Barcelona reúnen el 42\% de los efectivos laborales, proporción que supera el 50\% al incluir las de Valencia y Sevilla. Si las unidades espaciales son las áreas urbanas, las de Madrid y Barcelona representan el $41 \%$ del empleo español, superando de nuevo la mitad del total si se añaden Valencia, Sevilla y Bilbao. Por contra, en el $90 \%$ de las áreas urbanas del país no se alcanza el millar de empleos en estas actividades, que aún son más escasas en los espacios rurales. En suma, el territorio español no resulta en absoluto plano e indiferenciado al decidir estas empresas sus estrategias de localización, pues las externalidades asociadas a la aglomeración, la disponibilidad de capital humano o el valor simbólico concedido a ciertos espacios en las grandes ciudades limitan una deslocalización que sí afecta a otras actividades. 
Pero limitar la observación a las cifras de empleo impide confirmar que determinadas ciudades de tamaño intermedio también han conseguido un buen posicionamiento. El hecho de que las comprendidas entre 50.000 y 250.000 habitantes reúnan casi un millón de empleos, que equivalen al $31 \%$ del total (por un $27 \%$ de la población) señala una importancia aún más evidente al considerar su proporción en el empleo total de cada área urbana y la notable diversidad de especializaciones locales. Interpretar en profundidad las claves de esa compleja situación exigiría abordar análisis a escala local apoyados por el uso de técnicas cualitativas. Pero cabe ya apuntar la influencia ejercida por la dotación de recursos específicos y la trayectoria histórica de cada ciudad, tal como destacan los enfoques evolucionistas, las diversas estrategias de los actores locales y de las redes o coaliciones que establecen, priorizados por los enfoques relacionales, así como la influencia del marco normativo, el ambiente social y las políticas públicas, tal como destacan los enfoques neoinstitucionales (Sunley, 2008; MacKinnon et al., 2009).

Por último, el artículo también revisa de forma crítica ciertas afirmaciones que vinculan la presencia de este tipo de actividades con determinados efectos sobre el desarrollo socioeconómico de los territorios, utilizando para ello un análisis estadístico multivariante a escala provincial, que cuenta con mayor cantidad y variedad de información útil para ese objetivo. Se comprueba así que, aunque el volumen de afiliados en economía del conocimiento se correlaciona con el de población, empleo o producción, eso se deriva del predominio de actividades de servicios muy dependientes del efecto aglomeración, mientras las industrias intensivas en tecnología se asocian a territorios con mayor eficiencia productiva y nivel de ingresos. Por el contrario, la reducción de las tasas de paro o la mayor estabilidad en el empleo muestran escasa asociación con los restantes indicadores utilizados, incluida la presencia de titulados superiores, lo que cuestiona que la mayor cantidad de conocimiento en el trabajo derive necesariamente en una mejor calidad del empleo si no existe una regulación del mercado laboral que favorezca ese efecto.

En definitiva, enfrentar la crisis actual, derivada de una economía financiarizada y un crecimiento anómalo de sectores poco productivos, generadores de empleo precario e insostenibilidad ambiental, exige avanzar hacia una estructura productiva con mayor presencia de actividades intensivas en el uso del saber, generadoras de bienes o servicios de mayor valor. Ese objetivo sólo se conseguirá si al desarrollo de los sectores aquí considerados se suma la modernización de las actividades tradicionales para hacerlas también más eficientes y sostenibles. Pero, en todo caso, conocer la situación actual y la trayectoria de estos sectores en ciudades y regiones, comprender mejor sus factores de impulso o freno y contribuir a crear una conciencia social favorable a una economía renovada y un mejor empleo, coherentes con una nueva cultura del territorio, puede constituir un programa de investigación relevante para los próximos años, que exigirá complementar las panorámicas generales con estudios de caso y el uso de técnicas cualitativas que se aproximen mejor a la comprensión de estos procesos.

\section{BIBLIOGRAFÍA}

BOIX, R. et al. (2010): «The geography of creative industries in Europe: Comparing France, Great Britain, Italy and Spain», En 50th European Congress of the European Regional Science Association. Jonköping, ERSA. 
BOSCHMA, R.A. y KLOOSTERMAN, R.C. (Eds.) (2005): Learning from clusters: a critical assessment from an economic-geographical perspective. Berlín, Springer Verlag.

BRINKLEY, I. (2006): «Defining the knowledge economy». Knowledge Economy Programme Report. Londres, The Work Foundation.

CASTILLO, J.J. (2005): El trabajo recobrado. Una evaluación del trabajo realmente existente en España. Buenos Aires-Madrid, Miño y Dávila.

CUADRADO ROURA, J.R. y MAROTO, A. (2010): «Servicios y regiones en España». Estudios de la Fundación. Serie Economía y Sociedad, n 47, Madrid, Funcas.

FLORIDA, R. (2002): «The economic geography of talent», Annals of the Association of the American Geographers, vol. 92, no 4, 743-755.

FLORIDA, R. (2005): Cities and the creative class. Londres, Routledge.

GARRIDO, R. (2002): Cambio estructural y desarrollo regional en España. Madrid, Pirámide.

GLÜCKLER, J. y HAMMER, I. (2011): «A pragmatic service typology: capturing the disctintive dynamics of services in time and space». The Services Industries Journal, vol. 31, $\mathrm{n}^{\mathrm{o}} 6,941-957$.

KRÄTKE, S. (2007): «Metropolisation of the European economic territory as a consequence of increasing specialisation of urban agglomerations in the knowledge economy». European Planning Studies, vol. 15, $\mathrm{n}^{\circ}$ 1, 1-27.

LAROCHE, G. (2001): «Économie du savoir: mythe ou réalité». CETECH, Quebec (disponible en: http://www.cetech.gouv.qc.ca/publications/index.asp?categorie $=0701102 \#$ liste).

LÓPEZ. I. y RODRÍGUEZ, E. (2010): Fin de ciclo. Financiarización, territorio y sociedad de propietarios en la onda larga del capitalismo hispano (1959-2010). Madrid, Traficantes de Sueños, Observatorio Metropolitano.

MACKINNON, D.; CUMBERS, A.; PIKE, A.; BIRCH, K. y MCMASTER, R. (2009): «Evolution in economic geography: institutions, political economy and adaptation». Economic Geography, no $85,129-150$.

MACHLUP, F. (1962): The production and distribution of knowledge in the United States. Princeton, Princeton University Press.

MÉNDEZ, R. (Dir.) (2010): Estrategias de innovación industrial y desarrollo económico en las ciudades intermedias de España. Madrid, Fundación BBVA.

MÉNDEZ, R. y SÁNCHEZ MORAL, S. (2011): «Spanish cities in the knowledge economy: theoretical debates and empirical evidence». European Urban and Regional Studies, vol. $18, n^{\circ} 2,136-155$.

MUSTERD, S. y MURIE, A. (2010): Making competitive cities. Pathways, actors and policies. Londres, Blackwell.

OCDE (1996): Knowledge economy. París, OCDE.

PESQUERA, M. et al. (2010): Innovación empresarial, clase creativa y crecimiento económico en España. Valencia, Tirant lo Blanch.

ROMEIRO, P. y MÉNDEZ, R. (2008): «Las ciudades del conocimiento: revisión crítica y posibilidades de aplicación a las ciudades intermedias». Scripta Nova. Universidad de Barcelona, vol. XII, n 270 (50), 1-22.

SÁNCHEZ MORAL, S.; CALATRAVA, A. y MELERO, A.(2008): «Las funciones comando de Madrid en la economía global: una aproximación a través del proceso de atracción del capital extranjero». EURE, vol. XXXIV, núm. 101, 25-44. 
SCOTT, A. J. (2009): «Human capital resources and requirements across the metropolitan hierarchy of the USA». Journal of Economic Geography, n 9, 207-226.

SIMMIE, J. et al. (2008): History Matters: Path Dependence and Innovation in British City-Regions. Londres, NESTA.

STEHR, N. (2002): Knowledge and economic conduct. The social foundations of the modern economy. Toronto, University of Toronto Press.

SUNLEY, P. (2008): «Relational economic geography: a partial understanding or a new paradigm?» Economic Geography, nº 84, 1-26.

SWYNGEDOUW, E.; MOULAERT, F. y RODRÍGUEZ, A. (2002): «Neoliberal urbanization in Europe: large-scale urban development projects and the new urban policy» Antipode, vol. 34, n' $3,542-577$.

UNCTAD (2008): Creative Economy Report. Ginebra-Nueva York: UNCTAD.

VALE, M. (2011): «Innovation networks and local and regional development policy». En A. PIKE, A. RODRÍGUEZ-POSE y J. TOMANEY (Eds.). Handbook of local and regional development. Nueva York, Routledge, 413-424.

WINDEN, W. VAN; BERG, L. VAN DEN y POL, P. (2007): «European cities in the knowledge economy: towards a tipology». Urban Studies, vol. 44, nº. 3, 525-549. 